\title{
Mentoring: The Future of Higher Education?
}

\author{
Ana Sofia Saldanha \\ Universidade Autónoma de Lisboa, Portugal
}

\section{ABSTRACT}

Nowadays, University students all over Europe face a wide range of challenges either during their studies, or when they finish their Degrees. Throughout the cycle of studies, students have doubts regarding which career pathway to follow and how they can get some professional orientation towards the so wanted career and the so wanted success. Usually, these students have no idea of how the market in their area works, how to create a proper resumé, how to find suitable jobs according to their future aims or even how to choose a main area of interest.

(Most) Universities are not at all prepared to help these students to get a proper idea of the real professional world, and this is a major problem, however a problem with a very practical and professional solution: Mentoring.

Mentoring as a discipline incorporates features such as: Motivation, Expectation, Knowledge, Humbleness, Enthusiasm, Commitment, Willingness, Experience, Adequate Skills (regarding the working area), Adequate Training, Personal Skills, among others.

Nowadays, Mentoring is becoming a crescent area of interest and could and should be used in universities, even if as a specialized subject, to provide orientation, advice, guidance, help and even hope to the students who are studying in a specific area and want to try a career in that same area of studies, and to professionals who are working in a specific area/company and want to try a different pathway or to give a 360-degree turn to their life.

Therefore, and as a very effective and powerful tool, Mentoring improves motivation and motivation helps/improves a

career.

Mentoring should be adopted to transform the minds of the students and to show them they are good enough, important for the future and that they can (and will) become excellent and committed professionals if they have the right orientation and motivation.

These same professionals will pass a message to others in the future and that is when we will know that our efforts now will be fruitful in the years to come. 
Motivation is a central feature of Mentoring which $99 \%$ of the recently-graduated students do not possess at all, but they would love to. Motivation, as it is, has the following advantages: improves persistence and effort; improves initiative; improves cognitive processing skills and improves overall performance.

With persistence, effort, initiative, specific skills and an adequate performance, these students/professionals would have the will and the strength to start a career/make a change in a career. Unfortunately, however, these features are lacked and were not adequately developed during their studies and this is a barrier to develop themselves as persons and as committed professionals.

Keywords: Mentoring, Career, Motivation, Orientation, Professionalism 